\title{
Esophageal Motor Disorders Are a Strong and Independant Associated Factor of Barrett's Esophagus
}

\author{
Camille Bazin, ${ }^{1}$ Alban Benezech, ${ }^{1}$ Marine Alessandrini, ${ }^{2}$ Jean-Charles Grimaud, ${ }^{1,3}$ and Veronique Vitton ${ }^{1,3 *}$ \\ ${ }^{\text {I} S}$ Service de Gastroentérologie, Hôpital Nord, Assistance Publique - Hôpitaux de Marseille, Marseille, France; ${ }^{2}$ EA 3279 - Public Health, Chronic \\ Diseases and Quality of Life - Research Unit, Aix-Marseille Université, Marseille, France; and ${ }^{3}$ Plateforme d'Interface Clinique, CRN2M CNRS \\ UMR 7286, Aix-Marseille Université, Marseille, France
}

\section{Background/Aims}

Esophageal motor disorder (EMD) has been shown to be associated with gastroesophageal reflux disease (GERD). However, the association of EMD with a Barrett's esophagus (BE) is controversial. Our objective was to evaluate whether the presence of EMD was an independent factor associated with BE.

\section{Methods}

A retrospective case-control study was conducted in GERD patients who all had oeso-gastroduodenal endoscopy and high-resolution esophageal manometry. The clinical data collected was known or potential risk factors for BE: male gender, smoking and alcohol consumption, age, body mass index, presence of hiatal hernia, frequency, and age of GERD. EMD were classified according to the Chicago classification into: ineffective motor syndrome, fragmented peristalsis and absence of peristalsis, lower esophageal sphincter hypotonia.

\section{Results}

Two hundred and one patients (101 in the GERD + BE group and 100 in the GERD without BE) were included. In univariate analysis, male gender, alcohol consumption, presence of hiatal hernia, and EMD appeared to be associated with the presence of BE. In a multivariate analysis, 3 independent factors were identified: the presence of EMD (odds ratio [OR], 3.99; 95\% confidence interval [CI], 1.71-9.28; $P=0.001)$, the presence of hiatal hernia $(\mathrm{OR}, 5.60 ; 95 \% \mathrm{Cl}, 2.45-12.76 ; P<0.001)$, Helicobacter pylori infection $(\mathrm{OR}$, $0.08 ; 95 \% \mathrm{Cl}, 0.01-0.84 ; P=0.035)$.

\section{Conclusions}

The presence of EMD (particularly ineffective motor syndrome and lower esophageal sphincter hypotonia) is a strong independent associated factor of BE. Searching systematically for an EMD in patients suffering from GERD could be a new strategy to organize the endoscopic follow-up.

(J Neurogastroenterol Motil 2018;24:216-225)

\section{Key Words}

Barrett esophagus; Esophageal motility disorders; Gastroesophageal reflux

Received: July 27, 2017 Revised: December 27, 2017 Accepted: February 9, 2018

(.) This is an Open Access article distributed under the terms of the Creative Commons Attribution Non-Commercial License (http://creativecommons. org/licenses/by-nc/4.0) which permits unrestricted non-commercial use, distribution, and reproduction in any medium, provided the original work is properly cited.

*Correspondence: Veronique Vitton, MD, PhD

Service de Gastroentérologie, Hôpital Nord, Assistance Publique - Hôpitaux de Marseille, 13915 Marseille, France Tel: +33-10491965598, Fax: +33-10491965555, E-mail: vittonv@yahoo.com 


\section{Introduction}

Gastroesophageal reflux disease (GERD) is frequent in the general population. It has steadily increased since the 1990s, especially in North America and East Asia. ${ }^{1}$ Its average prevalence was estimated at $20 \%$ to $30 \%$ in 2017 in the Western countries.

Gastroesophageal reflux is defined by excessive exposure of the distal oesophagus to gastric contents. Even though it is usually a benign disease, GERD can nevertheless lead to complications such as peptic esophagitis and Barrett's esophagus, also known as Barrett's esophagus (BE). Because it can lead to the development of adenocarcinoma of the lower esophagus, the diagnosis of $\mathrm{BE}$ is of particular importance. Peptic esophagitis (with a prevalence of $40 \%$ to $50 \%$ in symptomatic patients with GERD) generally responds to medication using proton pump inhibitors, leading to a total regression of symptoms and healing of mucosal lesions in $70 \%$ of patients. $^{2}$ In BE, histology of biopsies shows that the squamous mucosa of the distal oesophagus is replaced with columnar mucosa and reveals intestinal metaplasia. ${ }^{2}$ It is observed in approximately $5 \%$ of patients with GERD and its incidence has increased constantly every year since the 1980 s. $^{3}$ The main risk of $\mathrm{BE}$ is its transformation into adenocarcinoma which is estimated at $0.3 \%$ per year. ${ }^{4}$ Thus, the presence of $\mathrm{BE}$ requires endoscopic surveillance according to its extent and to histology results. ${ }^{5}$

If GERD is the main risk factor for $\mathrm{BE}$, other factors linked to $\mathrm{BE}$ formation have been identified in literature. These factors are: male gender, Caucasian and/or Hispanic origins, being aged fifty or over, abdominal obesity, hiatus hernia and cigarette smoking. ${ }^{6}$ On the contrary, Helicobacter pylori infection could be a potential protective factor. ${ }^{7}$

Aside from this data, esophageal motor disorders, especially ineffective motility, have also been suspected to be risk factors for $\mathrm{BE}$ in patients with GERD. Effectively, hypomotility of the esophageal body is observed in patients with GERD and impaired esophageal clearance. The exposure of the esophageal lining to gastric contents would thus be increased, causing mucosal lesions. ${ }^{8,9}$ Nevertheless, esophageal motor disorders, such as esophageal body hypomotility or lower esophageal sphincter (LES) hypotonia, can be found in patients suffering from GERD. However, results in literature linking these disorders to BE remain contradictory. ${ }^{10-12}$

The main objective of this study is to evaluate the link between esophageal motor disorders, defined by esophageal high-resolution manometry (HRM) according to the Chicago classification, and the presence of $\mathrm{BE}$ in patients suffering from GERD.

\section{Materials and Methods}

\section{Patients}

In this retrospective, single-center case study, all patients suffering from GERD who had had upper gastrointestinal endoscopy and esophageal HRM were eligible. All examinations were carried out at the Hôpital Nord, Assistance Publique-Hôpitaux de Marseille, France.

Inclusion criteria were the following: aged $\geq 18$ years old, male or female, GERD symptoms defined by heartburn, acid reflux, postural syndrome as well as non-digestive symptoms such as those of the ear, nose, and throat region, breathing problems and/or chest pain, less than 12 months between esophageal HRM and upper gastrointestinal endoscopy, and for cases of BE, definition according to the Prague classification ${ }^{1}$ and confirmation by the pathology report.

Non-inclusion criteria were the following: aged $<18$ years old, auto-immune disease, diabetes, neurological disease, esophagitis (peptic, eosinophilic, caustic, or infectious), previous esophageal or thoracic surgery, a history of esophageal neoplasia (squamous cell carcinoma and/or adenocarcinoma), a history of loco-regional radiation therapy, previous treatment for $\mathrm{BE}$ (mucosectomy or radiofrequency ablation), a lapse of $>12$ months between oesophageal HRM and upper gastrointestinal endoscopy.

Exclusion criteria were the following: incomplete manometry, no pathology report available for $\mathrm{BE}$, the absence of an endoscopic description according to the Prague classification and the presence of adenocarcinoma in $\mathrm{BE}$ biopsies.

Clinical data collected were the following: reflux duration, use of proton pump inhibitors (PPI), body mass index (BMI), alcohol intake (never, occasionally, and daily), and cigarette smoking (never or active smoker, as well as accumulated intake given in packetsyear). A "never" or "occasionally" alcohol intake was not considered in the current study as a significant consumption and only patients with a daily consumption were considered as having an alcoholic intake.

\section{Gastroesophageal reflux disease questionnaire}

The GERD score is a specific self-administered questionnaire designed to evaluate the frequency of typical GERD symptoms. It is made up of 6 questions: 4 questions with a positive predictive value and 2 with a negative predictive value. ${ }^{14}$ Each answer is worth 0 to 3 points; the total score is therefore between 0 and 18 . A score 
of 8 points or over indicates a high probability of GERD with a specificity of $71.4 \%$ and a sensitivity of $64.6 \%$. This questionnaire was systematically filled out in the waiting room by all of the patients admitted for esophageal manometry and/or $\mathrm{pH}$ or $\mathrm{pH}$-impedance monitoring.

\section{Methods}

\section{Esophageal high-resolution manometry}

The HRM catheter contains 36 circumferential pressure sensors, regularly placed along the catheter, spaced 1 centimeter apart (Manoscan; Sierra Scientific Instruments Inc, Los Angeles, CA, USA). The catheter is placed transnasally and fixed in place once the correct position has been checked (identification of 2 highpressure zones, the upper esophageal sphincter [UES] and the esophago-gastric junction). With the catheter in place, the patient consecutively swallows $5 \mathrm{~mL}$ of water 10 times for a full study of esophageal peristalsis. Extensive data are collected at this stage. For our study we only retained data that was pertinent for GERD: the percentage of body waves transmitted and their amplitude, average resting pressure of the LES, intra-bolus pressure (IBP) which indirectly measures oesophageal clearance, and the distal contractile integral (DCI) in $\mathrm{mmHg} / \mathrm{sec} / \mathrm{cm}$ which defines the vigour of contractions. The catheter is linked to a computer installed with ManoView analysis software (Sierra Scientific Instruments Inc, Los Angeles, CA, USA) which gives a colour-coded read-out of oesophageal pressure.

All manometry was carried out and interpreted by the same competent operator. Eesophageal HRM is a technique for which reading, interpretation, and reproducibility are validated, a second reading was therefore not necessary.

\section{Manometric characterisation of oesophageal body mo- tor disorders (see Fig. 1)}

The manometric characterisation of esophageal body motor disorders was based on the Chicago classification version 3.0 adapted to the study of esophageal HRM results. ${ }^{15}$ This classification is currently the reference in all specialist centers.

Normal esophageal peristalsis is defined by $>50 \%$ peristaltic waves associated with LES relaxation during swallows.

Esophageal body motor disorders are defined below (Fig. 2):

(1) Ineffective motility syndrome: peristaltic waves not transmitted in $\geq 50 \%$ of swallows and Distal Integral Contraction $(\mathrm{DCI})<450$

(2) Fragmented peristalsis: peristaltic waves not transmitted in $\geq 50 \%$ of swallows with a large break (DCI $>450$ and axial breaks of over $5 \mathrm{~cm}$ in the $30 \mathrm{mmHg}$ isobaric contour).

(3) Absent peristalsis (major motor disorder): normal LES relaxation and total absence of contractility defined by DCI $<100$.

\section{Characterisation of the lower esophageal sphincter}

It was evaluated by measuring average resting pressure (normal between 13 and $43 \mathrm{mmHg}$ ).

Esophageal clearance is indirectly evaluated using IBP (in $\mathrm{mmHg}$ ) that is the intra-oesophageal measurement of ingested bolus pressure. Normal IBP is $<17 \mathrm{mmHg}$.

\section{Upper gastrointestinal endoscopy}

Upper gastrointestinal endoscopy, including the esophagus, stomach, and duodenum, was performed on all of the patients in this study. The BE segment was defined according to the Prague classification $^{14}$ : circumferential BE segment (C) and the longest BE tongue (M). Confirmation was provided by the pathology report of the biopsies carried out according to the Seattle protocol (systematic four-quadrant biopsies taken every $2 \mathrm{~cm}$ in circular zones, starting with the proximal extent of the gastric folds, and every centimeter for the tongues $)^{16}$ which classified $\mathrm{BE}$ as intestinal metaplasia, low-

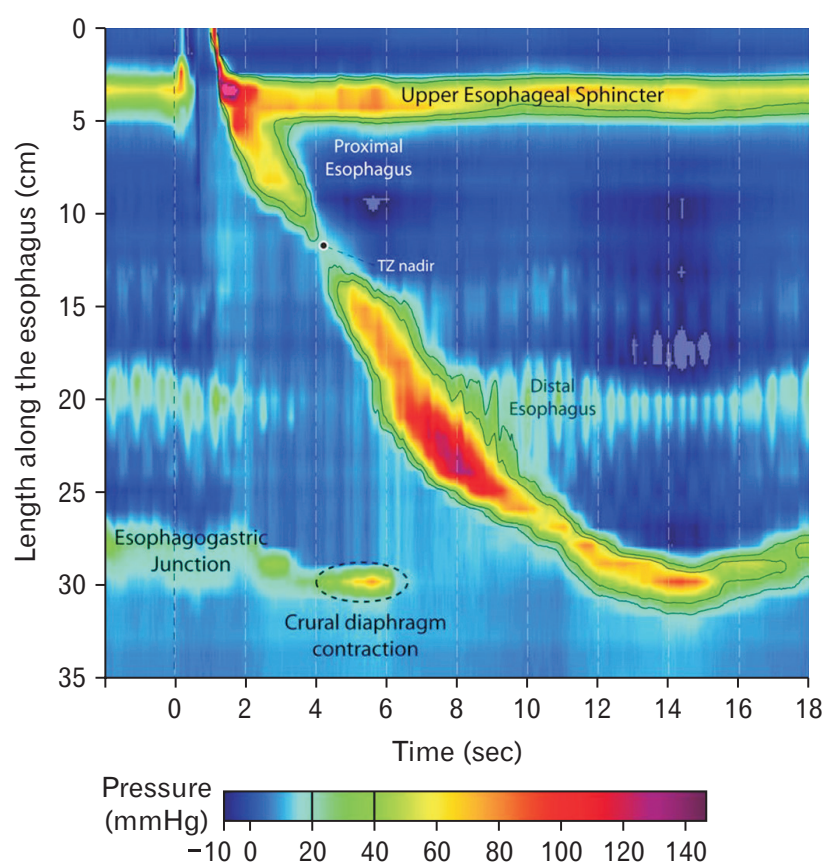

Figure 1. Esophageal high-resolution manometry patterns: normal pattern. UES, upper esophageal sphincter; EGJ, esophago-gastric junction. 

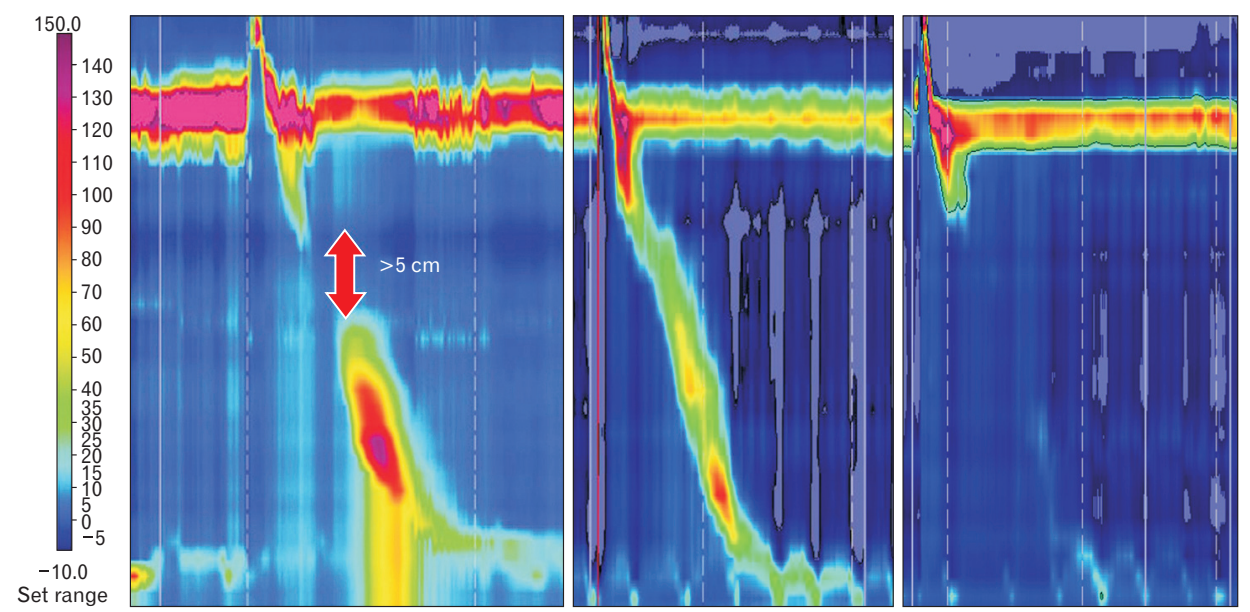

Figure 2. Esophageal high-resolution manometry patterns (from left to right): fragmented peristalsis with a large break $(>5 \mathrm{~cm})$, ineffective motility syndrome, and absence of peristalsis. Arrows represent the size of the break (in centimeters). grade or high-grade dysplasia. In the absence of dysplasia, the length of the Barrett's segment determines the frequency of endoscopic surveillance: none for $\mathrm{BE}<1 \mathrm{~cm}$, every 5 years for $1 \mathrm{~cm}$ $\leq \mathrm{BE}<3 \mathrm{~cm}$, every 3 years for $3 \mathrm{~cm} \leq \mathrm{BE}<10 \mathrm{~cm}$; for longer segments it is recommended to send the patient to consult a specialist center for adapted care. ${ }^{17}$

The presence of a hiatus hernia or any other macroscopic or histological disorder was noted.

\section{Esophageal pH monitoring}

Results from 24-hour $\mathrm{pH}$ or combined $\mathrm{pH}$-impedance monitoring were collected for patients who underwent these tests.

Patients stopped taking PPI or histamine $\mathrm{H} 2$ blockers 8 days prior to the test. The electrode was placed $5 \mathrm{~cm}$ above the LES and a 24-hour ambulatory monitoring was carried out. This test provides data on acid levels in the lower esophagus and also enables the study of a potential correlation of reflux with symptoms. An acid reflux episode is defined as a lapse of time (10 seconds minimum) during which the $\mathrm{pH}$ drops below 4 . A diary provides information on times of meals and changes of position (upright or recumbent). The sensitivity of this test for the detection of gastroesophageal reflux is between $77 \%$ and $100 \%$ and its specificity is between $85 \%$ and $100 \%$. For our study we collected data concerning significant acid reflux that was defined by more than $5 \%$ of the 24 hours recording time during which $\mathrm{pH}$ drops below $4 .{ }^{18}$

\section{Esophageal pH-impedance monitoring}

The esophageal $\mathrm{pH}$-impedance equipment contains a portable data recording device with $\mathrm{pH}$ and impedance amplifiers, and a catheter containing an antimony $\mathrm{pH}$ electrode and 6 impedance electrodes. The amplifier functions on a $1 \mathrm{kHz}$ to $2 \mathrm{kHz}$ alternat- ing current. Impedance and $\mathrm{pH}$ signals are recorded at a sample frequency of $50 \mathrm{~Hz}$ and the data are stored on a memory card. $\mathrm{pH}$ is measured $5 \mathrm{~cm}$ above the LES and impedance is measured in 6 different points above. The advantage of this test is to be able to realize it under PPI. However, because of the retrospective design of our study, and because in clinical practice, it is sometimes done without PPI, we have both recordings (some patients under PPI and some others without PPI). The advantage of this test is that it allows the measurement of acid and non-acid reflux. It also provides information on esophageal clearance illustrated by the time necessary for the reflux to be resolved. For our study we collected data concerning significant acid, non-acid or mixed reflux, as well as esophageal clearance disorders ( $>40$ seconds).

\section{Regulatory aspects}

This is a retrospective study and according to current French legislation on clinical trials, there was no need for patient consent. The data used were anonymized and collected from the Assistance Publique-Hôpitaux de Marseille computer file which is declared to the Commission Nationale Informatique et Liberté (French National Commission for Data Protection).

\section{Statistical Methods}

A descriptive analysis of the population was carried out: quantitative data was given as an average and standard deviation, or as a median with interquartile range (or with minimum and maximum values), qualitative data was given as a number or percentage. Comparative analysis of both groups (GERD and BE) was carried out using chi-square tests or Fisher's exact tests for qualitative data, or using Student's $t$ test, or a non parametric Mann-Whitney test when the $t$ test could not be applied, for quantitative data. 
We then carried out a multifactorial analysis to study factors associated with BE using backward stepwise logistic regression analysis. Variables were known risk factors for $\mathrm{BE}$ (age $\geq 50$ years old, male, cigarette smoking, and alcohol intake, BMI $\geq 25 \mathrm{~kg} / \mathrm{m}^{2}$ ) as well as variables selected from comparative analysis with $P \leq 0.20$ (gastric biopsies showing hiatus hernia and $H$. pylori). Models are given as odds ratios (OR) with $95 \%$ confidence intervals $(95 \% \mathrm{CI})$. Statistical analysis was performed using Predictive Analytics Software Statistics version 17.0.2 software (IBM Corp, Armonk, NY, USA). All tests were bilateral and the significance threshold was set at $5 \%$.

\section{Results}

\section{Clinical Data}

Two hundred and one patients were included in this study, 100 in the GERD + BE group and 101 in the GERD without BE group. Clinical and endoscopic data are shown in Table 1.

\section{Data From $\mathrm{pH}$ and Combined $\mathrm{pH}$-impedance Monitoring}

In total, 103 patients had at least one of these tests, 65 in the GERD without $\mathrm{BE}$ group (56 pH and $9 \mathrm{pH}$-impedance) and 38 in the GERD + BE group ( $28 \mathrm{pH}$ and $10 \mathrm{pH}$-impedance). Results are shown in Table 2.

\section{Manometric Data}

In total, 60 patients $(30.2 \%)$ presented with esophageal motor disorders (EMD).

The number of EMD was significantly higher in the GERD + $\mathrm{BE}$ group than in the GERD without BE group: respectively 45 (45.9\%) vs 15 (14.9\%), $P<0.001$. Results for HRM are shown in Table 3.

\section{Multivariate Analysis}

For multivariate analysis we included parameters identified in the literature as factors linked to BE: BMI $\left(\geq 25 \mathrm{~kg} / \mathrm{m}^{2}\right)$, age ( $\geq$ 50 years old), male gender, cigarette smoking and alcohol intake,

Table 1. Clinical, Endoscopic, and Pathology Data Comparing 2 Groups: Gastroesophageal Reflux Disease Without Barrett's Esophagus and Gastroesophageal Reflux Disease + Barrett's Esophagus

\begin{tabular}{|c|c|c|c|}
\hline & GERD without $\mathrm{BE}(\mathrm{n}=101)$ & GERD + BE $(n=100)$ & $P$-value \\
\hline Average age at esophageal HRM (yr) & $51.3 \pm 16.6$ & $51.7 \pm 15.9$ & 0.862 \\
\hline Male (n [\%]) & $33(32.7)$ & $46(46.9)$ & 0.040 \\
\hline Average $\mathrm{BMI}$ (average $\pm \mathrm{SD}, \mathrm{kg} / \mathrm{m}^{2}$ ) & $24.9 \pm 4.4$ & $25.2 \pm 3.9$ & 0.640 \\
\hline \multicolumn{4}{|l|}{ Cigarette smokers } \\
\hline Active (n $[\%])$ & $35(40.2)$ & $42(46.7)$ & 0.388 \\
\hline Accumulated intake (average $\pm \mathrm{SD}$, Packets-year) & $22.6 \pm 22.4$ & $18 \pm 15.6$ & 0.383 \\
\hline Alcohol intake (n [\%]) & $50(61)$ & $63(75.9)$ & 0.039 \\
\hline Taking PPI (n [\%]) & $72(87.8)$ & $84(87.5)$ & 0.951 \\
\hline GERD score (average $\pm \mathrm{SD}$, points) & $11 \pm 2.9$ & $10.9 \pm 3.5$ & 0.871 \\
\hline No. years with GERD median (interquartile range) & $10(3 ; 17)$ & $9.50(1 ; 4)$ & 0.998 \\
\hline Helicobacter pylori positive gastric biopsies (n [\%]) & $12(13.8)$ & $1(1.2)$ & 0.002 \\
\hline Hiatus hernia (n $[\%])$ & $26(28)$ & $58(67.4)$ & $<0.001$ \\
\hline \multicolumn{4}{|l|}{ BE Histology $(\%)$} \\
\hline Metaplasia without dysplasia & & $58(64.4)$ & \\
\hline Low-grade dysplasia & & $3(3.3)$ & \\
\hline High-grade dysplasia & & $1(1.1)$ & \\
\hline \multicolumn{4}{|l|}{ Prague classification } \\
\hline $\mathrm{C}$ (average $\pm \mathrm{SD}, \mathrm{cm})$ & & $0.8 \pm 2.1$ & \\
\hline $\mathrm{M}$ (average $\pm \mathrm{SD}, \mathrm{cm})$ & & $1.5 \pm 2.2$ & \\
\hline Number of tongues (average $\pm \mathrm{SD}$ ) & & $1.1 \pm 0.8$ & \\
\hline Short-segment BE (n [\%]) & & $90(97.8)$ & \\
\hline
\end{tabular}

GERD, gastroesophageal reflux disease; BE, Barrett's esophagus; HRM, high-resolution manometry; BMI, body mass index; C, circumferential BE segment; M, longest BE tongue. 
Table 2. Results for Different Parameters Recorded During pH and pH-impedance Tests Between 2 Groups: Gastroesophageal Reflux Disease Without Barrett's Esophagus and Gastroesophageal Reflux Disease + Barrett's Esophagus

\begin{tabular}{|c|c|c|c|}
\hline & GERD without $\mathrm{BE}$ & $\mathrm{GERD}+\mathrm{BE}$ & $P$-value \\
\hline $\mathrm{pH}$ monitoring (n [\%]) & $56(55.4)$ & $28(28)$ & \\
\hline Significant acid reflux (pH monitoring definition) (n [\%]) & $29(51.8)$ & $13(46.4)$ & 0.409 \\
\hline Gastric acid exposure of the lower oesophagus in $\%$ time over 24 hours (average $\pm \mathrm{SD}$ ) & $8.2 \pm 3.4$ & $13.1 \pm 10.9$ & 0.003 \\
\hline Average number of acid reflux episodes $>5$ min (average $\pm \mathrm{SD})$ & $2.8 \pm 2.4$ & $3.4 \pm 4.2$ & 0.407 \\
\hline pH-impedance monitoring (n [\%]) & $9(8.9)$ & $10(10.0)$ & \\
\hline Significant isolated acid reflux (n [\%]) & $0(0.0)$ & $3(30.0)$ & 0.124 \\
\hline Significant isolated non-acid reflux (n [\%]) & $3(33.3)$ & $0(0.0)$ & 0.087 \\
\hline Significant acid and non-acid reflux (n [\%]) & $3(33.3)$ & $1(10.0)$ & 0.249 \\
\hline Absence of significant reflux (n [\%]) & $3(33.3)$ & $6(60.0)$ & 0.242 \\
\hline Oesophagial clearance disorder (n [\%]) & $3(33.3)$ & $8(80.0)$ & 0.055 \\
\hline
\end{tabular}

GERD, gastroesophageal reflux disease; BE, Barrett's esophagus.

Table 3. Results for Different Manometric Parameters Recorded During Esophageal High-resolution Manometry in 2 Groups: Gastroesophageal Reflux Disease Without Barrett's Esophagus and Gastroesophageal Reflux Disease + Barrett's Esophagus

\begin{tabular}{|c|c|c|c|}
\hline & GERD without $\mathrm{BE}(\mathrm{n}=101)$ & GERD + BE $(n=100)$ & $P$-value \\
\hline Ineffective motility syndrome (n [\%]) & $8(8.0)$ & $26(26.5)$ & 0.001 \\
\hline Fragmented peristalsis (n [\%]) & $6(6.0)$ & $14(14.3)$ & 0.001 \\
\hline Absent peristalsis (n $[\%])$ & $1(1.0)$ & $5(5.1)$ & 0.001 \\
\hline Intra-bolus pressure in $\mathrm{mmHg}$ (median [interquartile range]) & $15(11 ; 18)$ & $12(8.25 ; 16.75)$ & 0.012 \\
\hline \multicolumn{4}{|l|}{ Lower oesophageal sphincter } \\
\hline Hypotonia (n [\%]) & $35(34.7)$ & $72(72.0)$ & $<0.001$ \\
\hline Average resting pressure in $\mathrm{mmHg}$ (median [interquartile range]) & $18(7.5 ; 27)$ & $9.3(4 ; 17.2)$ & 0.001 \\
\hline
\end{tabular}

GERD, gastroesophageal reflux disease; BE, Barrett's esophagus.

Table 4. Multivariate analysis for Different Parameters Between 2 Groups: Gastroesophageal Reflux Disease Without Barrett's Esophagus and Gastroesophageal Reflux Disease + Barrett's Esophagus

\begin{tabular}{|c|c|c|c|c|c|c|}
\hline & \multicolumn{3}{|c|}{ Univariate analysis } & \multicolumn{3}{|c|}{ Multivariate analysis } \\
\hline & $\begin{array}{l}\text { GERD without } \mathrm{BE} \\
\qquad(\mathrm{n}=101)\end{array}$ & $\begin{array}{l}\text { GERD with } \mathrm{BE} \\
\quad(\mathrm{n}=100)\end{array}$ & $P$-value & OR & CI $95 \%$ & $P$-value \\
\hline Age $\geq 50$ years at oesophageal HRM (n [\%]) & $54(54)$ & $53(53.0)$ & 0.887 & 0.66 & $0.29-1.51$ & 0.324 \\
\hline Male (n $[\%])$ & $33(32.7)$ & $46(46.9)$ & 0.040 & 1.23 & $0.54-2.83$ & 0.622 \\
\hline $\mathrm{BMI} \geq 25 \mathrm{~kg} / \mathrm{m}^{2}(\mathrm{n}[\%])$ & $41(48.2)$ & $53(58.2)$ & 0.184 & 1.96 & $0.86-4.44$ & 0.108 \\
\hline \multicolumn{7}{|l|}{ Cigarette smokers } \\
\hline Active (n [\%]) & $35(40.2)$ & $42(46.7)$ & 0.388 & 0.974 & $0.42-2.26$ & 0.952 \\
\hline Daily or occasional alcohol intake (n [\%]) & $50(61.0)$ & $63(75.9)$ & 0.039 & 1.90 & $0.75-4.82$ & 0.174 \\
\hline Hiatus hernia (n $[\%])$ & $26(28.0)$ & $60(67.4)$ & $<0.001$ & 5.60 & $2.45-12.76$ & $<0.001$ \\
\hline Helicobacter pylori positive gastric biopsies (n [\%]) & $12(13.8)$ & $1(1.2)$ & 0.002 & 0.080 & $0.008-0.84$ & 0.035 \\
\hline Presence of EMD (n [\%]) & $15(14.9)$ & $45(45.9)$ & $<0.001$ & 4.49 & $1.85-10.93$ & 0.001 \\
\hline
\end{tabular}

GERD, gastroesophageal reflux disease; BE, Barrett's esophagus; HRM, high-resolution manometry; BMI, body mass index.

presence of $H$. pylori, and hiatus hernia.

This analysis enabled us to show that the presence of EMD was an associated factor independent of BE with: OR, 3.9; $95 \%$
CI, 1.7-9.3; $P=0.001$.

The presence of $H$. pylori in gastric biopsies and the presence of hiatus hernia were 2 other factors which were significantly as- 
sociated with the presence of $\mathrm{BE}$ (respectively $\mathrm{OR}, 0.08$; 95\% CI, $0.008-0.84 ; P=0.035$ and $\mathrm{OR}, 5.60 ; 95 \% \mathrm{CI}, 2.45-12.76 ; P<$ $0.001)$.

The other factors studied were not significantly associated with BE.

Detailed results are provided in Table 4.

\section{Discussion}

To our knowledge, this is the first study showing that the esophageal motor disorder is a significantly associated factor independent of $\mathrm{BE}$ in patients suffering from GERD.

In this retrospective, single-center, case study we compared the clinical and manometric data of patients suffering from GERD without complications, and of patients suffering from GERD and BE. The frequency of GERD symptoms was assessed using the validated GERD score. The endoscopic description of BE was based on the Prague classification which is the current standard reference in clinical practice providing guidelines for endoscopic surveillance. ${ }^{14}$ In our study, all manometric examinations were carried out using HRM, because it enables the description of new esophageal motor disorders according to the Chicago classification. ${ }^{16}$ From what we know, the majority of studies assessing esophageal motor disorders in BE did not use HRM. Moreover, all of the HRM was carried out in the same center and interpreted by the same operator, thus ensuring uniform interpretation.

Currently, factors associated with BE identified in the literature are, other than having Caucasian or Hispanic origins: male gender, cigarette smoking, age, abdominal obesity, hiatus hernia, severity, and duration of GERD. ${ }^{10,17,19,20}$ In our study, univariate analysis showed that male gender, alcohol intake and hiatus hernia appeared to be associated with $\mathrm{BE}$. These results are consistent with those found in the literature for the male gender, ${ }^{21}$ however the association with alcohol intake remains a controversial issue which may vary with gender, ethnic origins and the type of alcohol being drunk. ${ }^{22-26}$ A significantly more frequent presence of hiatus hernia in our study complies with previously published articles. ${ }^{27,28}$ This observation can probably be explained by the fact that hiatus hernia prevents the esophago-gastric junction from acting as a barrier preventing acid gastric contents from rising into the esophagus, thus encouraging the onset of GERD. Our results also support data showing the absence of $H$. pylori infection in patients with GERD and BE; however this data remains contended in scientific literature. ${ }^{29-31}$

On the contrary, univariate analysis in this study did not show any significant association between $\mathrm{BE}$ and age, gender, cigarette smoking, BMI, the duration, or the frequency of GERD symptoms. If the age of patients does not appear to be associated with $\mathrm{BE}$, it is, however, concordant with the average age at which $\mathrm{BE}$ is observed. ${ }^{28,32}$ Average BMI was not significantly different between the 2 groups of patients. This supports scientific papers which retain the increase in visceral fat rather than $\mathrm{BMI}$ as a risk factor for $\mathrm{BE}^{33,34}$ which is in fact considered to be a factor for GERD but not directly linked to $\mathrm{BE}$. $^{35}$ Unfortunately, due to the retrospective aspect of our study, evaluation of visceral fat, not a current practice, was not available. We did not find a link either of $\mathrm{BE}$ with duration and frequency of GERD symptoms, whereas this is commonly reported in the literature. ${ }^{36,37}$ Multivariate analysis, for the factors stated above, only significantly linked the presence of hiatus hernia and the absence of $H$. pylori infection to the presence of $\mathrm{BE}$.

Concerning $\mathrm{pH}$ monitoring data, our results were not completely in agreement with those found in the iterature; ${ }^{38-42}$ effectively, only the percent of lower esophagus exposure to gastric acid in time over 24 hours was significantly higher in the BE group. The results of combined $\mathrm{pH}$-impedance were not significantly different between the 2 groups. However, among the 201 patients included in the current study, only 84 patients underwent $\mathrm{pH}$ monitoring (56 in the GERD without BE group and 28 in the GERD + BE group), and only 19 (9 in the GERD without BE group and 10in the GERD + BE group) underwent combined $\mathrm{pH}$-impedance. This limit is due to the retrospective design of our study and our results may thus be explained by the bias brought about by the fact that not all of the patients underwent these tests. Indeed, the knowledge of all parameters are of importance to evaluate the risk of BE.

The main result of our study is to have demonstrate a significant, independent link between the presence of EMD and BE. Esophageal motor disorders are known to be present in GERD. The most frequent disorders observed are hypomotility of the esophageal body and/or LOS hypotonia. ${ }^{43-45}$ The type of motor disorders observed in our study corresponds to those previously reported in the literature, since we observed ineffective motility syndrome (IMS), fragmented peristalsis, absence of peristalsis and LOS hypotonia. ${ }^{44}$ The pathophysiological explanation would be that motor disorders in the esophageal body would disrupt esophageal clearance, thus increasing the time of exposure of the esophagus to acid gastric contents. ${ }^{44,46}$ However, current scientific knowledge is not able to conclude whether EMDs are the cause or the consequence of GERD. On one hand, some studies have shown the reversibility of esophageal body motor disorders and of LOS hypotonia following endoscopic healing of esophagitis. ${ }^{47-49} \mathrm{On}$ the other hand, EMD persisted in patients with esophagitis after 
healing in different studies, suggesting that EMD could be the cause of GERD, or that some types of EMD may be irreversible after particularly aggressive and prolonged exposure of the esophagus to gastric acid. It has been found that an aggravation of esophageal mucosal lesions with GERD is concomitant with an increase in EMD prevalence (mainly IMS) and a decrease in esophageal clearance. ${ }^{15,45}$ This data was confirmed for patients with $\mathrm{BE}$ in comparison with patients suffering from GERD without $\mathrm{BE} .^{50,51}$

Nevertheless, even though EMDs are widely reported, the link between their presence and the onset of complications, especially $\mathrm{BE}$, remains controversial. ${ }^{38}$ Our study is, therefore, the first to show that EMD is an associated, independent factor of $\mathrm{BE}$. We consider that this result is particularly important to be taken into account, given the fact that $\mathrm{BE}$ is a feared preneoplastic lesion for which there are few known and modifiable predictive, or specifically associated factors. Thus, the identification of associated factors would enable GERD surveillance according to these identified, predictive factors for BE. Esophageal HRM provides a more precise description of EMD using the Chicago classification. A better apprehension of EMD enables better comprehension of GERD pathophysiology but also, as suggested by Gyawali et al, ${ }^{39}$ enables the study of esophageal motility in GERD in 3 distinct steps: evaluation of OGJ (normal, hiatus hernia, LOS hypotonia or both), evaluation of esophageal body motility (normal, IMS, fragmented or absent peristalsis) and evaluation of esophageal body contraction reserve (contraction reserve present or not, data not available in our study); in this way EMD fall into different phenotypes according to the 3 elements given above. This recent apprehension of GERD pathophysiology thanks to esophageal HRM firstly has potential therapeutic interest especially for anti-reflux surgery. Effectively, even if surgery can play a part in preventing BE, by stopping intestinal metaplasia from evolving into dysplasia, and even by causing low-grade dysplasia to regress. ${ }^{52,53}$ it remains questionable and even not recommended for patients with "major" esophageal motor disorders. Secondly, results obtained using esophageal HRM in GERD should be taken into account when setting up a surveillance strategy for patients with EMD. If, indeed, the presence of EMD is associated with the onset of $\mathrm{BE}$, systematic screening could be offered so as to define a rhythm of surveillance according to the presence or not of EMD for patients with known BE risk factors.

However, if our study shows that EMD is an associated, independent factor for $\mathrm{BE}$, we cannot talk about a predictive factor, given the retrospective aspect of our study. Prospective studies on large series of patients would need to be carried out, to enable the identification of EMD as a risk factor for the onset of $\mathrm{BE}$.
In conclusion, our study is the first to show that the presence of EMD, notably IMS and lower esophageal sphincter hypotonia, is an independent factor associated with BE. The evolution of esophageal high resolution manometry has enabled the identification of not one, but several phenotypes of GERD, via the different manometric defects observed, that can thus be integrated into adapted therapeutic strategies. If our results are confirmed, EMD investigation could become an indispensable parameter in GERD assessment, in order to set up EMD endoscopic surveillance to detect complications such as $\mathrm{BE}$.

\section{Financial support: None.}

\section{Conflicts of interest: None.}

Author Contributions: Camille Bazin wrote the paper, performed the research, and collected and analysed data ; Alban Benezech wrote the paper and analysed the data; Marine Alessandrini collected and analysed the data; Jean-Charles Grimaud performed the research; and Veronique Vitton performed the research, analysed data, and wrote the paper.

\section{References}

1. El-Serag HB, Sweet S, Winchester CC, Dent J. Update on the epidemiology of gastro-oesophageal reflux disease: a systematic review. Gut 2014;63:871-880.

2. Frazzoni L, Fuccio L, Frazzoni M. Proton pump inhibitor-refractory gastroesophageal reflux disease: current diagnosis and management. Minerva Gastroenterol Dietol 2017;63:249-256.

3. Rex DK, Cummings OW, Shaw M, et al. Screening for Barrett's esophagus in colonoscopy patients with and without heartburn. Gastroenterology 2003;125:1670-1677.

4. Shalauta MD, Saad R. Barrett's esophagus. Am Fam Physician 2004.

5. Weusten B, Bisschops R, Coron E, et al. Endoscopic management of Barrett's esophagus: European Society of Gastrointestinal Endoscopy (ESGE) Position Statement. Endoscopy 2017;49:191-198.

6. Rubenstein JH. Risk factors for Barrett's esophagus. Curr Opin Gastroenterol 2014;30:408-414.

7. Arora Z, Garber A, Thota PN. Risk factors for Barrett's esophagus. J Dig Dis 2016;17:215-221.

8. Oberg S, DeMeester TR, Peters JH, et al. The extent of Barrett's esophagus depends on the status of the lower esophageal sphincter and the degree of esophageal acid exposure. J Thorac Cardiovasc Surg 1999;117:572-580.

9. Steevens J, Schouten LJ, Driessen ALC, et al. A prospective cohort study on overweight, smoking, alcohol consumption, and risk of Barrett's esophagus. Cancer Epidemiol Biomarkers Prev 2011;20:345-358.

10. Martínek J, Benes M, Hucl T, Drastich P, Stirand P, Spicák J. Non- 
erosive and erosive gastroesophageal reflux diseases: No difference with regard to reflux pattern and motility abnormalities. Scand J Gastroenterol 2008;43:794-800.

11. Chen CL, Yi CH, Cook IJ. Differences in oesophageal bolus transit between patients with and without erosive reflux disease. Dig Liver Dis 2008;40:348-354.

12. Frazzoni M, De Micheli E, Zentilin P, Savarino V. Pathophysiological characteristics of patients with non-erosive reflux disease differ from those of patients with functional heartburn. Aliment Pharmacol Ther 2004;20:81-88.

13. Alvarez Herrero L, Curvers WL, van Vilsteren FG, et al. Validation of the Prague C\&M classification of Barrett's esophagus in clinical practice. Endoscopy 2013;45:876-882.

14. Jones R, Junghard O, Dent J, et al. Development of the GerdQ, a tool for the diagnosis and management of gastro-oesophageal reflux disease in primary care. Aliment Pharmacol Ther 2009;30:1030-1038.

15. Savarino E, de Bortoli N, Bellini M, et al. Practice guidelines on the use of esophageal manometry - A GISMAD-SIGE-AIGO medical position statement. Dig Liver Dis 2016.

16. American Gastroenterological Association, Spechler SJ, Sharma P, Souza RF, Inadomi JM, Shaheen NJ. American Gastroenterological Association medical position statement on the management of Barrett's esophagus. Gastroenterology 2011;140:1084-1091.

17. Corley DA, Kubo A, Levin TR, et al. Race, ethnicity, sex and temporal differences in Barrett's oesophagus diagnosis: a large community-based study, 1994-2006. Gut 2009;58:182-188.

18. Picon L, Bruley Des Varannes S; Groupe de Travail sur les Recommandations pour lapratique de la pHmétrie esophagienne. [Guidelines for esophageal pH-monitoring in adults.] Gastroenterol Clin Biol 2000;24:931-943. [French]

19. Ford AC, Forman D, Reynolds PD, Cooper BT, Moayyedi P. Ethnicity, gender, and socioeconomic status as risk factors for esophagitis and Barrett's esophagus. Am J Epidemiol 2005; 162:454-460.

20. Cook MB, Shaheen NJ, Anderson LA, et al. Cigarette smoking increases risk of Barrett's esophagus: an analysis of the Barrett's and Esophageal Adenocarcinoma Consortium. Gastroenterology 2012;142:744-753.

21. Cook MB, Wild CP, Forman D. A systematic review and meta-analysis of the sex ratio for Barrett's esophagus, erosive reflux disease, and nonerosive reflux disease. Am J Epidemiol 2005;162:1050-1061.

22. Ren LL, Yan TT, Wang ZH, et al. Alcohol consumption and the risk of Barrett's esophagus: a comprehensive meta-analysis. Sci Rep 2015;5:16048.

23. Matsuzaki J, Suzuki H, Kobayakawa M, et al. Association of visceral fat area, smoking, and alcohol consumption with reflux esophagitis and Barrett's esophagus in Japan. PLoS One 2015;10:e0133865.

24. Xu Q, Guo W, Shi X, et al. Association between alcohol consumption and the risk of Barrett's esophagus: a meta-analysis of observational studies. Medicine (Baltimore) 2015;94:e1244.

25. Anderson LA, Cantwell MM, Watson RGP, et al. The association between alcohol and reflux esophagitis, Barrett's esophagus, and esophageal adenocarcinoma. Gastroenterology 2009;136:799-805.

26. Kubo A, Levin TR, Block G, et al. Alcohol types and sociodemographic characteristics as risk factors for Barrett's esophagus. Gastroenterology 2009; 136:806-815.

27. Martinucci I, de Bortoli N, Giacchino M, et al. Esophageal motility abnormalities in gastroesophageal reflux disease. World J Gastrointest Pharmacol Ther 2014;5:86-96.

28. Frazzoni M, Manno M, De Micheli E, Savarino V. Pathophysiological characteristics of the various forms of gastro-oesophageal reflux disease. Spectrum disease or distinct phenotypic presentations? Dig Liver Dis 2006;38:643-648.

29. Weston AP, Badr AS, Topalovski M, Cherian R, Dixon A, Hassanein RS. Prospective evaluation of the prevalence of gastric Helicobacter pylori infection in patients with GERD, Barrett's esophagus, Barrett's dysplasia, and Barrett's adenocarcinoma. Am J Gastroenterol 2000;95:387-394.

30. Lord RV, Frommer DJ, Inder S, Tran D, Ward RL. Prevalence of Helicobacter pylori infection in 160 patients with Barrett's oesophagus or Barrett's adenocarcinoma. Aust N Z J Surg 2000;70:26-33.

31. Iwakiri K, Sugiura T, Hayashi Y, et al. Esophageal motility in Japanese patients with Barrett's esophagus. J Gastroenterol 2003;38:1036-1041.

32. Savarino E, Gemignani L, Pohl D, et al. Oesophageal motility and bolus transit abnormalities increase in parallel with the severity of gastrooesophageal reflux disease. Aliment Pharmacol Ther 2011;34:476-486.

33. Corley DA, Kubo A, Levin TR, et al. Abdominal obesity and body mass index as risk factors for Barrett's esophagus. Gastroenterology 2007;133:34-41.

34. Kubo A, Cook MB, Shaheen NJ, et al. Sex-specific associations between body mass index, waist circumference and the risk of Barrett's oesophagus: a pooled analysis from the international BEACON consortium. Gut 2013;62:1684-1691.

35. Hampel H, Abraham NS, El-Serag HB. Meta-analysis: obesity and the risk for gastroesophageal reflux disease and its complications. Ann Intern Med 2005;143:199-211.

36. Thrift AP, Kramer JR, Qureshi Z, Richardson PA, El-Serag HB. Age at onset of GERD symptoms predicts risk of Barrett's esophagus. Am J Gastroenterol 2013;108:915-922.

37. Lagergren J, Bergström R, Lindgren A, Nyrén O. Symptomatic gastroesophageal reflux as a risk factor for esophageal adenocarcinoma. $\mathrm{N}$ Engl J Med 1999;340:825-831.

38. Karvelis KC, Drane WE, Johnson DA, Silverman ED. Barrett esophagus: decreased esophageal clearance shown by radionuclide esophageal scintigraphy. Radiology 1987;162(1 Pt 1):97-99.

39. Gyawali CP, Roman S, Bredenoord AJ, et al. Classification of esophageal motor findings in gastro-esophageal reflux disease: conclusions from an international consensus group. Neurogastroenterol Motil Published Online First: 24 May 2017. doi: 10.1111/nmo.13104.

40. Triadafilopoulos G, Tandon A, Shetler KP, Clarke J. Clinical and pH study characteristics in reflux patients with and without ineffective oesophageal motility (IEM). BMJ open Gastroenterol 2016;3:e00126.

41. Zentilin P, Conio M, Mele MR, et al. Comparison of the main oesophageal pathophysiological characteristics between short- and long-segment Barrett's oesophagus. Aliment Pharmacol Ther 2002;16:893-898.

42. Ji Hyang Kim, Poong Lyul Rhee, Sung Noh Hong et al. [The relationship between esophageal motility disorder and pathologic acid exposure.] 
Kor J Neurogastroenterol Motil 2005;11:28-32. [Korean]

43. Ho SC, Chang CS, Wu CY, Chen GH. Ineffective esophageal motility is a primary motility disorder in gastroesophageal reflux disease. Dig Dis Sci 2002;47:652-656.

44. Diener U, Patti MG, Molena D, Fisichella PM, Way LW. Esophageal dysmotility and gastroesophageal reflux disease. J Gastrointest Surg Off J Soc Surg Aliment Tract 2001;5:260-265.

45. Chan WW, Haroian LR, Gyawali CP. Value of preoperative esophageal function studies before laparoscopic antireflux surgery. Surg Endosc 2011;25:2943-2949.

46. Lin S, Ke M, Xu J, Kahrilas PJ. Impaired esophageal emptying in reflux disease. Am J Gastroenterol 1994;89:1003-1006.

47. Shirazi S, Schulze-Delrieu K, Custer-Hagen T, Brown CK, Ren J. Motility changes in opossum esophagus from experimental esophagitis. Dig Dis Sci 1989;34:1668-1676.

48. Cao W, Cheng L, Behar J, et al. Proinflammatory cytokines alter/reduce esophageal circular muscle contraction in experimental cat esophagitis.
Am J Physiol Gastrointest Liver Physiol 2004;287:G1131-G1139.

49. Eastwood GL, Castell DO, Higgs RH. Experimental esophagitis in cats impairs lower esophageal sphincter pressure. Gastroenterology 1975;69:146-153.

50. Parrilla P, Ortiz A, Martinez de Haro LF, Aguayo JL, Ramirez P. Evaluation of the magnitude of gastro-oesophageal reflux in Barrett's oesophagus. Gut 1990;31:964-967.

51. Ang D, Blondeau K, Sifrim D, Tack J. The spectrum of motor function abnormalities in gastroesophageal reflux disease and Barrett's esophagus. Digestion 2009;79:158-168.

52. Chang EY, Morris CD, Seltman AK, et al. The effect of antireflux surgery on esophageal carcinogenesis in patients with barrett esophagus: a systematic review. Ann Surg 2007;246:11-21.

53. Rossi M, Barreca M, de Bortoli N, et al. Efficacy of Nissen fundoplication versus medical therapy in the regression of low-grade dysplasia in patients with Barrett esophagus: a prospective study. Ann Surg 2006;243:58-63. 